from upper social class families it is still not certain that this alone would explain their extra height.

Before looking at UKALL II we made a preliminary study of a small cohort of 35 of our local patients and showed them also to be taller than normal (standard deviation score $=+0.51, \mathrm{P}<0.005$ ). Here we can say there was no evident class bias, at least, not of the degree that would be necessary to cause such a significant difference in height in such a small group. Also we are tempted to point out that no correlation between height and social class was found in the children studied by McWhirter et al. While that is probably a reflection of a small sample size, it could be taken to indicate that class does not affect height in leukaemic children, perhaps because other influences override it.

We feel forced to conclude that at present the question of whether social class is responsible for leukaemic children being tall cannot be answered. Indeed, whether they are tall is still in question in view of other reports failing to confirm our findings. Clearly what is needed is a large prospective multicentre study to settle both points.

\section{Earlier recognition of abnormal stature}

\section{Sir,}

Any attempt to identify and treat short children is to be applauded. I therefore strongly support the Oxford screening chart designed by Drs Aynsley Green and

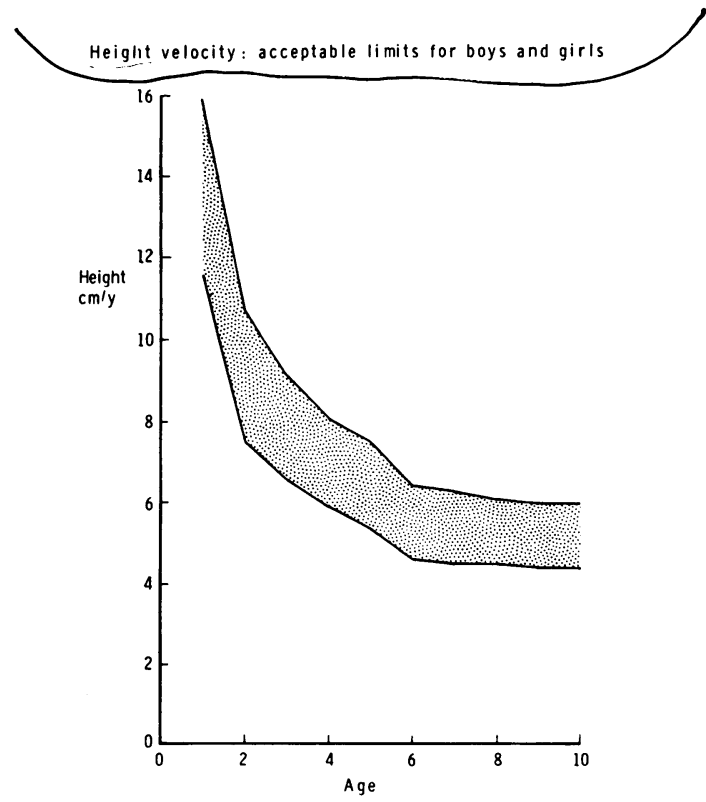

How to use this chart

1. Measure height on two occasions.

2. Plot the rate of growth $(\mathrm{cm} /$ year) against the age of the child midway between the two measurements.

e $g$ Heights measured at ages 4 and 6 show a difference of $12 \mathrm{~cm}$.

Rate is $6 \mathrm{~cm} /$ year which should be plotted at age 5 .

3. Seek advice for rates falling outside the hatched area.

Figure Height velocity chart.
MacFarlane. ${ }^{1}$ My concern about this approach is that it identifies a child once he has already become short. In many instances, this is too late because even if the cause is found and treated, the ultimate result depends on how much growth has already been lost in the process of identifying the child.

I think that it is preferable to screen for growth problems on the basis of height velocity measurements because these may identify children who may not yet be absolutely short but who already need attention because they are growing badly. The Figure shows the chart which we have introduced in child health clinics in Brent for this purpose, and I offer it as an alternative to the more absolute screen proposed by Aynsley Green and MacFarlane.

\section{Reference}

1 Aynsley Green A, MacFarlane JA. Method for the earlier recognition of abnormal stature. Arch Dis Child $1983 ; 58: 535-7$.

Charles G D Brook The Middlesex Hospital, Mortimer Street, London WIN $8 A A$

\section{Lithium toxicity in the newborn}

Sir,

We were interested in the papers by Wilson, Forfar, and Godman $^{1}$ and by Morrell et al. ${ }^{2}$ because in 1974 we published a case of transplacental lithium poisoning ${ }^{3}$ that was diagnosed antenatally by noting an irregular and often slow fetal heart. In that paper we made two points which are worth repeating because of the current interest in this subject.

Firstly, although controlling the mothers' serum values in pregnancy is desirable, it must be stressed that normal values do not exclude toxicity in the newborn. Normal maternal values were found in the patient we reported and in others in the published reports, although the two in the Archives both had concentrations of lithium in maternal blood above the normal adult therapeutic range.

Secondly, because bradycardia and irregularity of the fetal heart may be caused by lithium toxicity, these signs do not necessarily mean fetal distress if the mother is receiving this drug.

\section{References}

1 Wilson N, Forfar JC, Godman MJ. Atrial flutter in the newborn resulting from maternal lithium ingestion. Arch Dis Child 1983;58:538-9.

2 Morrell P, Sutherland GR, Buamah PK, Oo M, Bain HH. Lithium toxicity in a neonate. Arch Dis Child 1983;58: 539-41.

3 Stevens D, Burman D, Midwinter A. Transplacental lithium poisoning (letter). Lancet 1974 ;ii:595.

David Stevens, David Burman, AND AUDREY MIDWINTER Bristol Maternity Hospital, Bristol BS2 8BJ 